\title{
20 \\ Achieving greater gains in biodiversity from agri-environment schemes
}

\section{Philip Gibbons}

\section{Key lessons}

- Agri-environment schemes should focus on investments that maximise gains in biodiversity relative to the status quo.

- It is widely viewed that our conservation priorities should be biodiversity that has high values of irreplaceability (biodiversity that must be protected to achieve conservation targets) and has high vulnerability (the likelihood that biodiversity will be lost without conservation investment).

- Too much agri-environmental investment is in biodiversity that is not vulnerable to loss, and this investment does not result in substantial gains to biodiversity relative to the status quo.

- Agri-environment schemes should be informed by a decision framework that calculates gains in biodiversity relative to the status quo (i.e. the difference in biodiversity with investment and losses without investment). This will shift more investment from large, high-quality remnants to smaller, more modified remnants that are more vulnerable to loss. 


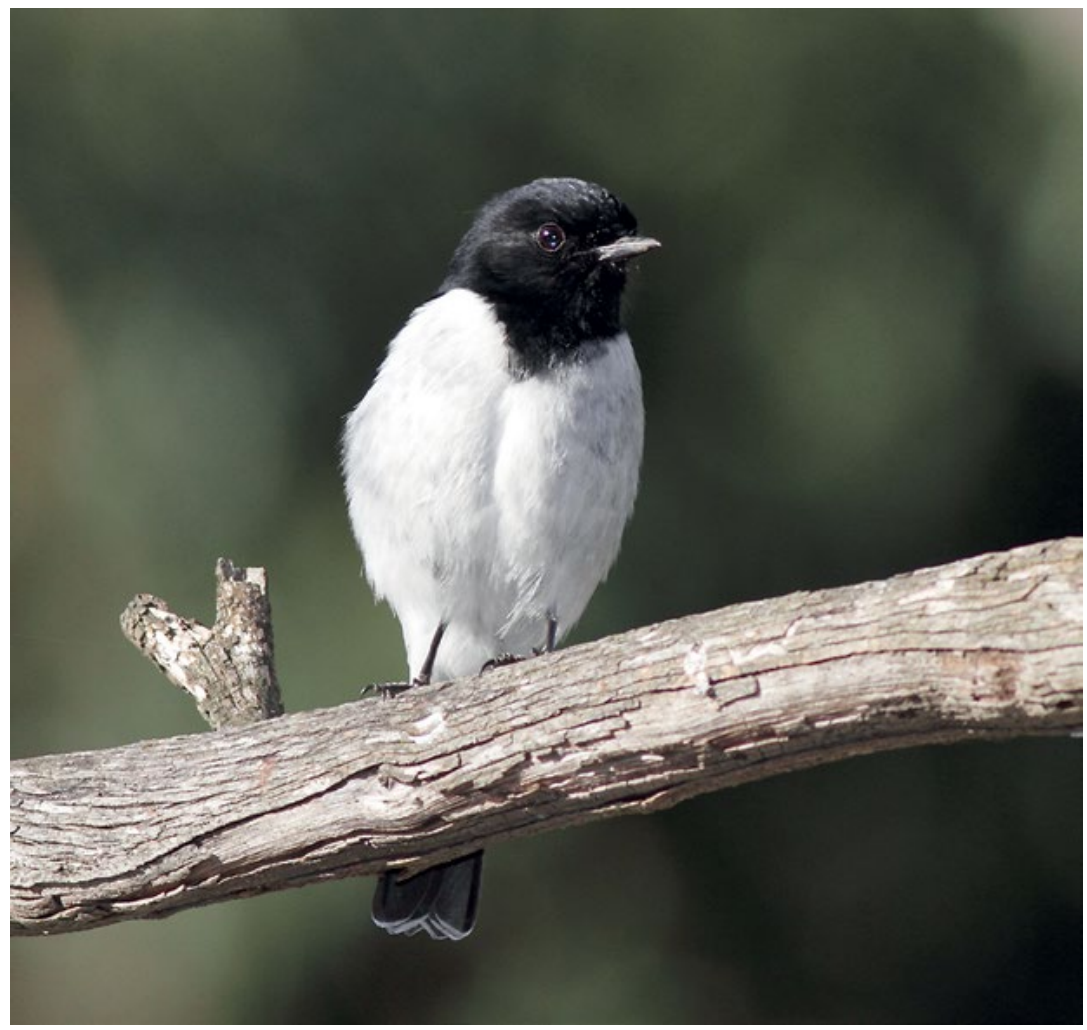

Figure 20.1: Increasing the conservation status of threatened species such as the hooded robin (Melanodryas cucullata) is a key motivation for many agri-environment schemes.

Source: Photo by Geoff Park.

If I was to invest in a farm, I would not invest in the largest farm on the market, but a farm with greatest potential to return growth on my investment. In this chapter, I argue that our current investment strategy for biodiversity in agri-environment schemes is frequently the opposite: we tend to invest in sites that support large amounts of biodiversity, rather than sites with potential to return the greatest gains in biodiversity as a result of the investment (Figure 20.2). 

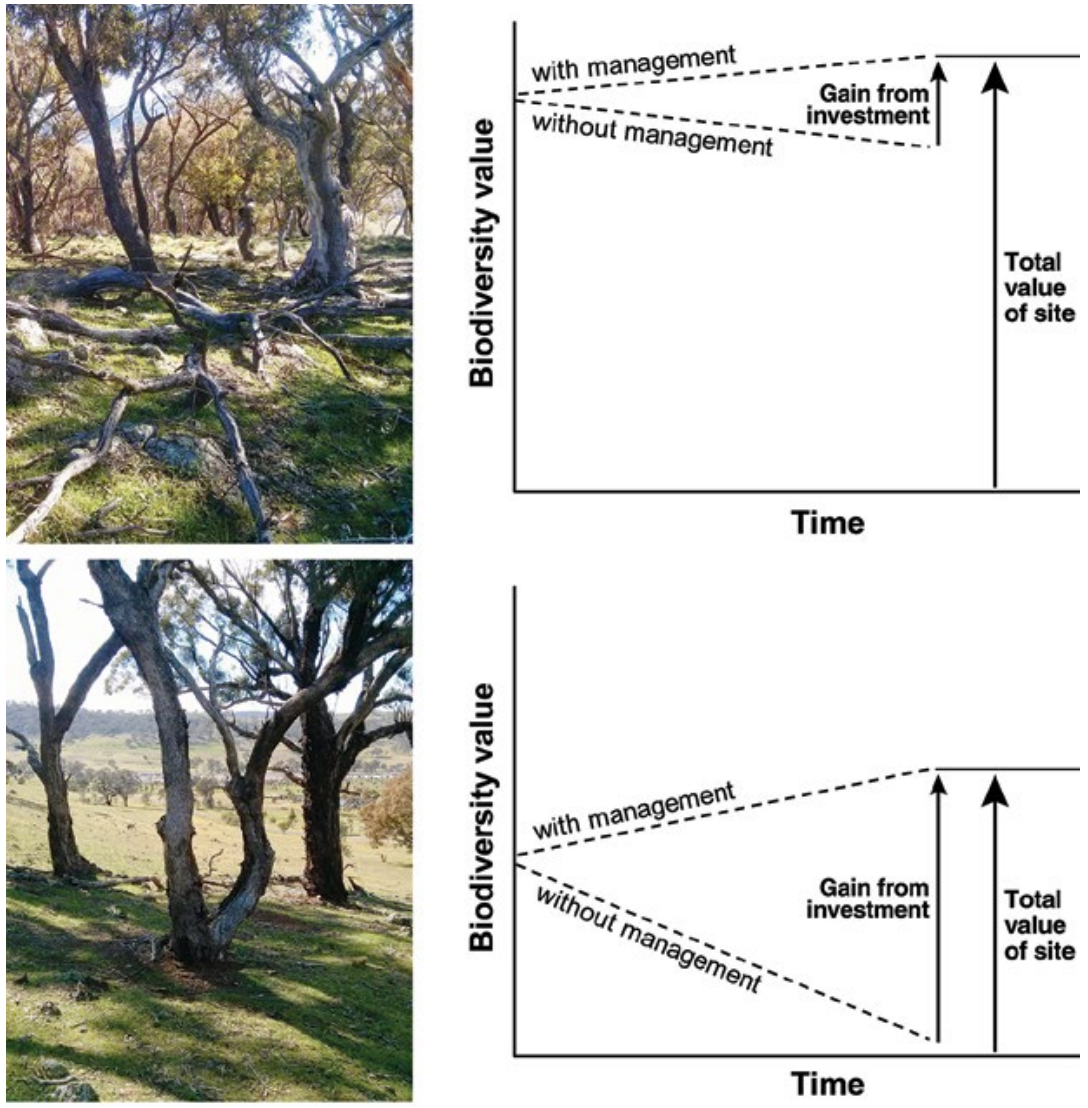

Time

Figure 20.2: Agri-environment schemes often prioritise sites for investment based on the total biodiversity that occurs on a site, rather than the gain in biodiversity that is likely to occur with investment. The former approach places priority for investment in high-quality sites (top), while the latter places priority on moderate-quality sites (bottom).

Source: Author's research.

\section{The theory of biodiversity prioritisation}

Historically, there has been a bias in protected areas within Australia towards land unsuitable for agriculture. Australia's reserves therefore tend to protect areas that are steep and/or infertile (Pressey et al. 2002). As a consequence, one-third of Australia's bioregions are very poorly represented (less than 5 per cent) in Australia's National Reserve 
System (Hatton et al. 2011). Many of the most poorly protected ecosystems in Australia occur in agricultural landscapes. Margules and Pressey (2000) outline the principles upon which future conservation investment should be based to rectify past biases. These and other authors argue that our conservation priorities should be those areas, or elements of biodiversity, that have highest values of irreplaceability and vulnerability (Figure 20.3).

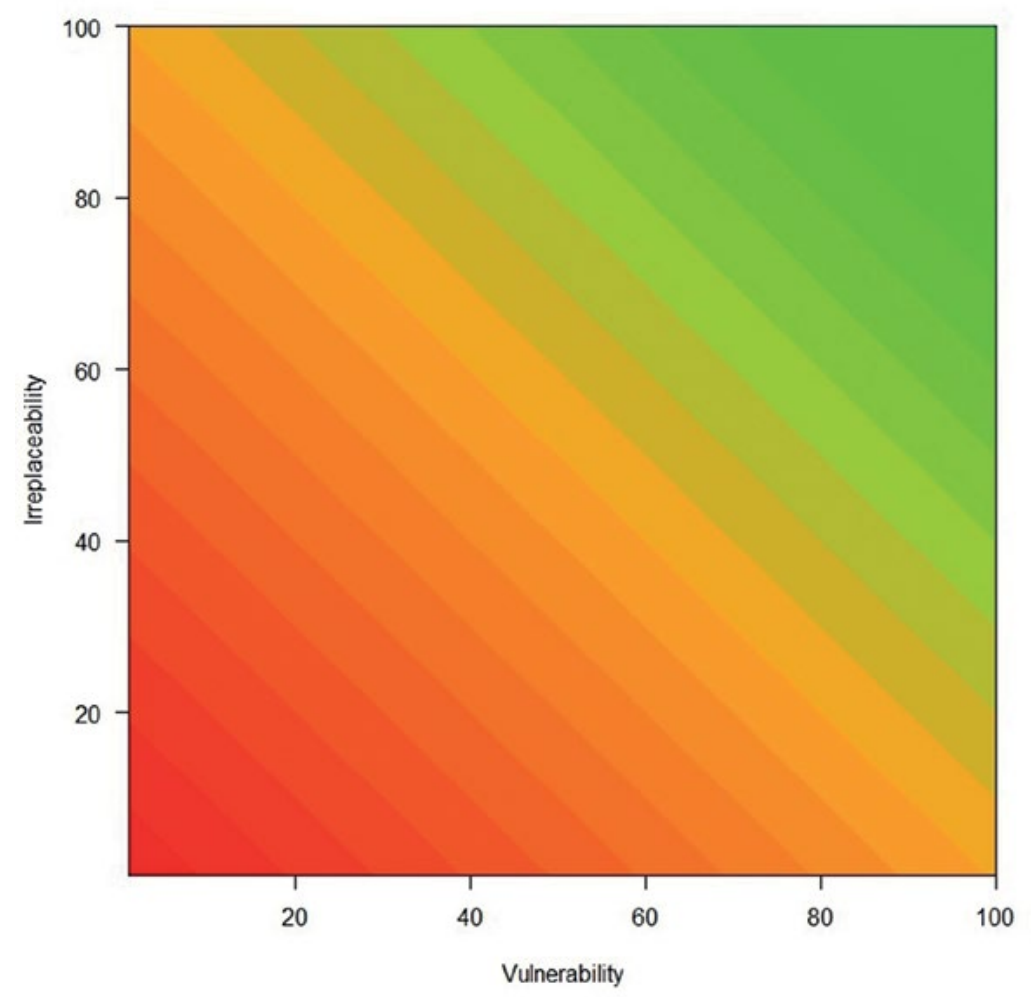

Figure 20.3: Higher priorities for conservation are those sites that have high irreplaceability and high vulnerability, as indicated in green.

Source: Author's research.

Irreplaceability refers to the likelihood that a site must be protected to meet a conservation target. This concept is analogous to complementarity (Margules and Pressey 2000), which is the extent to which an area contributes unrepresented biota to a reserve system. For example, if the conservation target is to protect at least 17 per cent of the original (pre-European) extent of each ecosystem, and less than 
17 per cent remains of a particular ecosystem, then all remaining remnants of this particular ecosystem are 100 per cent irreplaceable. That is, all examples of this ecosystem that are left are required to meet the conservation target.

Vulnerability refers to the likelihood that a site will be lost without immediate conservation investment (Margules and Pressey 2000). This principle is based on the assumption that the areas and actions needed to secure biodiversity exceed the resources available for conservation and thus we need to prioritise our conservation investment in those areas or for those actions that are most urgent. For example, a remnant in which natural regeneration has ceased due to a land use such as livestock grazing - and will disappear over time - is more vulnerable than a remnant in which natural regeneration is still occurring.

\section{Where is our current biodiversity investment in agri-environment schemes?}

The principle of irreplaceability has been embraced within Australia. We now tend to prioritise our conservation investment in biota that are poorly represented in our existing protected area network (National Reserve System Task Group 2009) and this thinking is reflected in agri-environment schemes. For example, the Environmental Stewardship Program (see Chapter 3) focused on ecological communities poorly represented in Australia's National Reserve System. However, the concept of vulnerability has not been embraced as fully. For example, BushTender is the most established agri-environment scheme focused on biodiversity in Australia, with over 35,000 ha managed for conservation on private land. The metric that underpins the way sites are prioritised for investment in BushTender multiplies the current condition of a site by the condition that the site is likely to achieve with investment (Maron et al. 2013). That is, other things being equal, a site that can be improved from 20 to 80 out of 100, will score less $(20 \times 80=1,600)$ than a site that can be improved from 70 to 90 out of $100(70 \times 90=6,300)$ even though the gain in biodiversity at the latter site (20) is a third of the gain achieved on the former site (60). In this metric, the total value of the site for biodiversity is given more weight than the gain in biodiversity that will be achieved. If the metric was instead based only on the gain in biodiversity at each site, then a site that can be improved from 20 to 80 of 100 (with a gain of 60) will be 
prioritised for investment over a site that can be improved from 70 to 90 (with a gain of 20). These two scenarios are illustrated conceptually in Figure 20.2. Similarly, the investment strategy underpinning the Australian Government's Environmental Stewardship Program for Box Gum Grassy Woodland in south eastern Australia stipulated that remnants must be at least 10 ha. Focusing agri-environmental investment on patches greater than 10 ha could result in most of the remaining area of this ecological community being lost. This is because most of this ecological community (at least in the southern part of its range) occurs in much smaller patches (Gibbons and Boak 2002), and these smaller patches are more likely to be approved for clearing (Gibbons et al. 2009) and are least likely to contain natural regeneration (Weinberg et al. 2011). Maron et al. (2013) identifies other metrics that result in similar outcomes. Given this, our agri-environmental investment may not be returning the gains in biodiversity that are possible.

\section{Where should we be investing?}

There is a bias in agri-environmental investment towards large, highquality remnants for three key reasons: (1) there is an assumption that all remnants on private land are equally vulnerable to loss; (2) there is an assumption that small remnants and poor-quality remnants are of limited value for conservation relative to large remnants; and (3) managing fewer, larger remnants is considered more cost-effective than managing more, small remnants. These assumptions should be considered critically.

On the first point - the assumption that all remnants on private land are equally vulnerable to loss - not all biodiversity on private land that is highly irreplaceable is also vulnerable to loss. For example, the larger remnants of our most cleared ecosystems have not been cleared because they tend to occur on sites with low productivity and are therefore neither intensively grazed, nor profitable to clear or fertilise, and are not as vulnerable to invasion by exotic plants than more productive sites. It is also important to acknowledge that there is legislation that affords a high level of protection to these sites, and it is important that agri-environment schemes do not undermine this existing duty of care. In contrast, smaller remnants of these ecological communities are very vulnerable to loss because they tend to be on more productive land, under greater threat from land management 
practices in the agricultural matrix (Driscoll et al. 2013), have a lower likelihood of supporting natural regeneration (Weinberg et al. 2011), and are more likely to be approved for clearing (Gibbons et al. 2009).

On the second point, there is a widely held view that small sites, poorquality sites, and highly fragmented landscapes are of limited value for conservation. For example, the Habitat Hectares metric (Parkes et al. 2003) that underpins agri-environmental investment in Victoria affords greater score or value to larger patches and more intact landscapes. However, the species-area curve (Rosenzweig 1995) predicts that adding a unit area of habitat to a smaller patch or more fragmented landscape will result in a greater increase in species than improving or adding the same amount of habitat to a larger patch or intact landscape (Figure 20.4). This prediction has been recently confirmed for birds in agricultural landscapes within Australia (e.g. Cunningham et al. 2014; Huth and Possingham 2011). A counter argument is that conservation efforts in small remnants will favour only common species. While this argument might hold for dispersal-limited species, small patches make an important contribution to the conservation of declining birds (Fischer and Lindenmayer 2002).

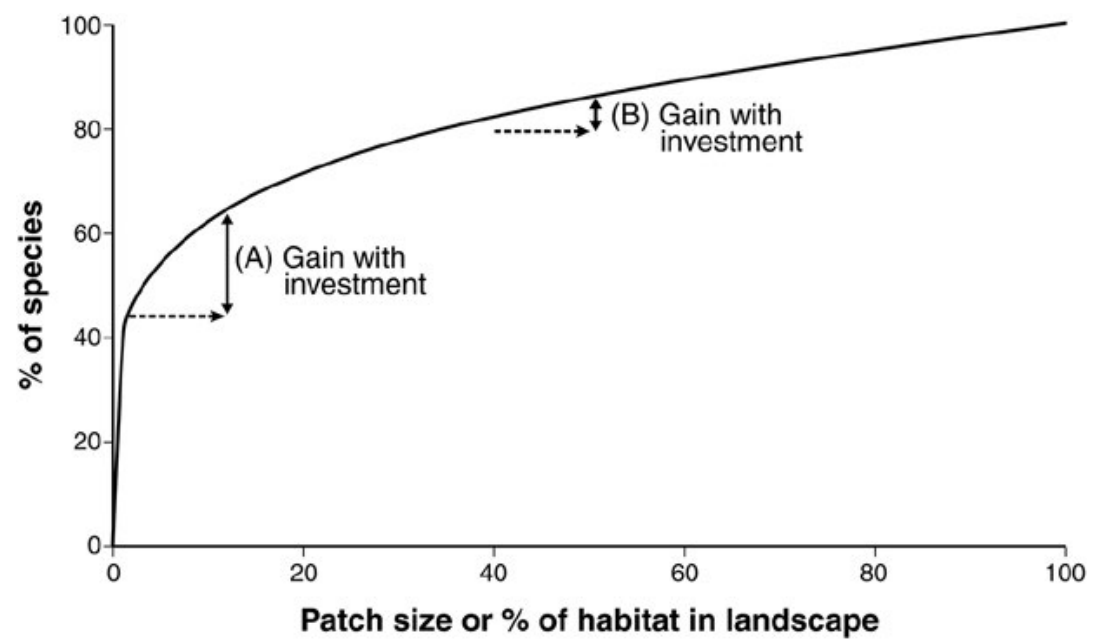

Figure 20.4: A generic species-area curve (using an exponent of 0.25 ) indicating the predicted gain in species richness with the same conservation effort (indicated by arrows) in (A) a smaller patch or highly cleared landscape compared with (B) a larger patch or more intact landscape.

Source: Author's research. 
Finally, large sites are considered to be more cost-effective to manage than small sites. However, if the cost-effectiveness of investments are considered in agri-environment schemes (i.e. biodiversity gain is divided by cost), then a higher cost of management (per ha) on smaller sites could be offset by a higher rate of gain in biodiversity. Results from the Australian Government's Environmental Stewardship Program found that the cost (per ha) of tenders to manage biodiversity on private land were similar for small and large remnants (Whitten et al. 2009). That is, no discernible economy of scale was observed. This may be because the unit of management for agri-environment schemes is effectively the farm rather than the individual remnant - and thus is influenced by characteristics of the farming enterprise rather than the individual remnant. However, more sites may be more costly to administer (e.g. more assessments) or manage where infrastructure (e.g. fencing) is required.

\section{Conclusion}

Agricultural areas of Australia support many highly irreplaceable ecosystems that are vulnerable to loss, and these landscapes are important for biodiversity conservation. Investment in biodiversity conservation through agri-environment schemes makes intuitive sense. However, the amount of investment in agri-environment schemes is unlikely to be sufficient to meet our conservation targets, so we must prioritise this investment carefully. Shifting the focus of agri-environmental investment towards activities that are likely to return the greatest gains in biodiversity (i.e. the difference with investment and losses without investment) is likely to see a greater emphasis on investment in smaller, modified remnants and more fragmented landscapes than is currently the case.

\section{References}

Cunningham, R.B., D.B. Lindenmayer, M. Crane, et al. (2014) 'The law of diminishing returns: Woodland birds respond to native vegetation cover at multiple spatial scales and over time' Diversity and Distributions 20: 59-71. 
Driscoll, D.A., S.C. Banks, P.S. Barton, D.B. Lindenmayer and A.L. Smith (2013) 'Conceptual domain of the matrix in fragmented landscapes', Trends in Ecology and Evolution 28: 605-13.

Fischer, J. and D.B. Lindenmayer (2002) 'Small patches can be valuable for biodiversity conservation: Two case studies on birds in southeastern Australia', Biological Conservation 106: 129-36.

Gibbons, P. and M. Boak (2002) 'The value of paddock trees for regional conservation in an agricultural landscape', Ecological Management and Restoration 3: 205-10.

Gibbons, P., S. Briggs, D. Ayers, et al. (2009) 'An operational method to assess impacts of land clearing on terrestrial biodiversity', Ecological Indicators 9: 26-40.

Hatton, T., S. Cork, P. Harper, et al. (2011) 'Australia state of the environment 2011', independent report to the Australian Government Minister for the Environment and Heritage, Canberra.

Huth, N. and H.P. Possingham (2011) 'Basic ecological theory can inform habitat restoration for woodland birds', Journal of Applied Ecology 48: 293-300.

Margules, C.R. and R.L. Pressey (2000) 'Systematic conservation planning', Nature 415: 243-53.

Maron, M., J.R. Rhodes and P. Gibbons (2013) 'Calculating the benefit of conservation actions', Conservation Letters 6: 359-67.

National Reserve System Task Group (2009) Strategy for Australia's National Reserve System 2009-2030, Department of the Environment, Water, Heritage and the Arts, Canberra.

Parkes, D., G. Newell and D. Cheal (2003) 'Assessing the quality of native vegetation: The "habitat hectares" approach', Ecological Management and Restoration 4: S29-S38.

Pressey, R., G. Whish, T. Barrett and M. Watts (2002) 'Effectiveness of protected areas in north-eastern New South Wales: Recent trends in six measures', Biological Conservation 106: 57-69.

Rosenzweig, M.L. (1995) Species diversity in space and time, Cambridge University Press, Melbourne. 
Weinberg, A., P. Gibbon, S.V. Briggs and S.P. Bonser (2011) 'The extent and pattern of Eucalyptus regeneration in an agricultural landscape', Biological Conservation 144: 227-33.

Whitten, S.M., R. Gorddard, A. Langston and A. Reeson (2009) A review of the Box Gum Grassy Woodlands Environmental Stewardship Project Metric, report for the Australian Government Department of the Environment, Water, Heritage and the Arts, CSIRO Sustainable Ecosystems, Canberra. 
This text is taken from Learning from agri-environment schemes in Australia: Investing in biodiversity and other ecosystem services on farms, edited by Dean Ansell, Fiona Gibson and David Salt, published 2016 by ANU Press, The Australian National University, Canberra, Australia. 